\title{
Postoperative Bleeding Complications in Patients on Novel Oral Anticoagulants and Vitamin K Antagonist Following an Invasive Dental Procedure - A Review of Literature
}

\author{
Pavithra $\mathrm{M}^{1}$, Arvind Muthukrishnan ${ }^{2}$ \\ ${ }^{1,2}$ Department of Oral Medicine and Radiology, Saveetha Dental College and Hospitals, \\ Saveetha Institute of Medical and Technical Science, Chennai, Tamil Nadu, India.
}

\section{ABSTRACT}

The incidence of thromboembolic diseases is high. It is one of the leading causes of death and disability. Anticoagulants are used for preventing or reducing blood clot formation and treatment of other related thrombotic disorders. Vitamin $\mathrm{K}$ antagonists (VKA) were developed more than 60 years ago. Warfarin is the most commonly used VKA. The drawbacks of vitamin $\mathrm{K}$ antagonists were that it requires frequent monitoring and dose adjustments, food and drug interactions, narrow therapeutic range, diet restrictions.

For the past 15 years, various new drugs have been introduced to overcome the disadvantages of vitamin $\mathrm{K}$ antagonists. In 2008, a new group of anticoagulants were introduced. They are known as novel anticoagulants (NOAC) or direct oral anticoagulants. They include dabigatran, apixaban, rivaroxaban and edoxaban. The major issue with NOAC is difficulty in monitoring the dose. A literature search was done on this topic. It is very important for the dentists to know the bleeding complications in patients under anticoagulant therapy. The dental treatment of patients who tend to have an increased risk of bleeding due to the use of anticoagulants and / or antiplatelet drugs raises a challenge in the daily practice of dental professionals. According to current evidence, there is no significant difference in postoperative bleeding between novel anticoagulants and vitamin $\mathrm{K}$ antagonists. The risk of thromboembolic events on stopping the anticoagulants should be assessed. Local haemostatic measures are shown to suffice to control possible bleeding secondary to dental treatments.

\section{KEY WORDS}

Anticoagulants; Apixaban; Dabigatran; Dentistry; Edoxaban; Rivaroxaban.
Corresponding Author: Dr. M. Arvind, Professor and Head of Oral Medicine and Radiology Department, Saveetha Institute of Medical and Technical Science, Chennai, Tamil Nadu, India.

E-mail: arvindmuthukrishnan@yahoo.com

DOI: $10.14260 / j e m d s / 2021 / 621$

How to Cite This Article: Pavithra M, Muthukrishnan A. Postoperative bleeding complications in patients on novel oral anticoagulants and vitamin $k$ antagonist following an invasive dental procedure - a review of literature. $J$ Evolution Med Dent Sci 2021;10(35): 3047-3052, DOI:

$10.14260 /$ jemds/2021/621

Submission 25-04-2021,

Peer Review 29-06-2021,

Acceptance 05-07-2021,

Published 30-08-2021.

Copyright @ 2021 Pavithra M. et al. This is an open access article distributed under Creative Commons Attribution License [Attribution 4.0 International (CC BY 4.0)] 


\section{BACKGROUND}

The incidence of thromboembolic diseases is high. It is one of the leading causes of death and disability. There are two types of clots. ${ }^{1,2}$ Arterial clot is made up of rich platelets and poor fibrin is usually generated at the site of vascular injury. These clots are responsible for stroke (transient ischemic attack) and myocardial infarction. The other type is a venous clot, which is made up of fibrin and red blood cells. These clots are responsible for deep vein thrombosis and pulmonary embolism. ${ }^{3}$ Primary prevention of these diseases includes lifestyle modifications, cessation of smoking, alcohol, avoidance of high-fat diet, exercise, reduction of weight, physical activity and appropriate dietary habits. ${ }^{4}$ In addition to all this, pharmacotherapy plays a major role in prevention and treatment to reduce morbidity and mortality. Anticoagulants are used for these conditions, to prevent blood hypercoagulability. There are various types of anticoagulants available in the market. During the 1950s, warfarin was used as an anticoagulant for heart attack and stroke. It is highly recommended in cases of atrial fibrillation. ${ }^{5}$ Other vitamin $\mathrm{K}$ antagonists include phenprocoumon, acenocoumarol. Apart from warfarin, heparins have been used for decades in the management of thromboembolic disorders. They include low molecular weight heparin and unfractionated heparin. The drawbacks of vitamin $\mathrm{K}$ antagonists are it requires frequent monitoring and dose adjustments, food and drug interactions, narrow therapeutic range and diet restrictions. For the past 15 years, there have been numerous new drugs that have been introduced to overcome the disadvantages of vitamin $\mathrm{K}$ antagonists. ${ }^{6}$

In 2008, a new group of anticoagulants were introduced. They are known as novel anticoagulants or direct oral anticoagulants. ${ }^{7}$ These drugs have lower drug concentration, no food interactions, rapid onset, are easy to discontinue and start the drug immediately, no need for regular monitoring and have a wide therapeutic range. ${ }^{8}$ DOACs is the preferred name according to the International Society of Thrombosis and Haemostasis. ${ }^{9}$ Initially, thrombin inhibitors (Dabigatran) was introduced, which targeted Factor IIa. Thrombin is the key enzyme in the coagulation mechanism. It is mainly used in the prevention of systemic embolism and stroke. Then the other set of drugs were introduced which specifically targeted Factor Xa. They are apixaban, rivaroxaban and edoxaban. The major issue with NOAC is difficulty in monitoring the dose. ${ }^{10}$

The dentists need to know the bleeding complications in patients under anticoagulant therapy. Previous studies have demonstrated that in the case of dental procedures, the risk of thrombotic events due to altering or discontinuing antithrombotic therapy far outweighs the low risk of potential perioperative bleeding complications among patients treated with single or dual antiplatelet therapy or vitamin $\mathrm{K}$ antagonists. ${ }^{11} \mathrm{~A}$ cross-sectional study reported that the dentists were aware of the management with traditional anticoagulants and antiplatelet agents, but there was a lack of knowledge about the new group of drugs. ${ }^{12}$ Most dentists overestimate the bleeding risk, which suggests that there is a need for dental education programmes and further training in this topic.
To our knowledge, there were only limited studies published on the difference between postoperative bleeding complications in patients on different anticoagulant drugs followed by an invasive dental procedure. Therefore, the main purpose of this review is to provide a summary of NOAC and assess whether there is any difference between postoperative bleeding complications in patients on NOAC and vitamin $\mathrm{K}$ antagonists following an invasive dental procedure.

\section{Vitamin K Antagonist}

They were developed more than 60 years ago. Warfarin is the most commonly used VKA. It is an oral drug that acts by inhibiting the enzyme called VKORC1 (Vitamin K epoxide reductase complex ${ }^{1}$ It is very important for the activation of available vitamin $\mathrm{K}$ in our body. ${ }^{13}$ By this mechanism, there will be a reduction in the synthesis of active clotting factors. It can reduce the recurrence of venous thromboembolism by more than $90 \%$ and stroke (transient ischemic attack) in non - valvular atrial fibrillation by $60 \%$. Franchini M et al. 2014 reported that there is a decrease in the risk of bleeding events by the usage of genotype-guided initial VKA. There are some disadvantages of VKA despite their excellent clinical results. ${ }^{14}$ It has a narrow therapeutic range, often interacts with food and drugs, frequent laboratory monitoring of the INR (International Normalized Ratio), and needs frequent dose adjustments. ${ }^{15}$

Numerous studies were investigating the management of patients under VKA for dental interventions. Recent evidence suggests that the dosage of VKAs should not be altered before dental treatment. The American College of Chest Physicians (ACCP) recent guidelines suggest that dental procedures can be done without VKA interruption. In case of bleeding, haemostatic agents can be used. Similarly, British guidelines suggest that there is no need for discontinuation of VKA before the dental procedures. Many randomized controlled and prospective studies were done on this topic. Most of them concluded that the risk of stopping the VKA outweighs the risk of bleeding followed by the dental procedure.15,16 Based on this current evidence, it is clear that dental procedures that are unlikely to cause bleeding can be done without interruption of VKA. In case of high bleeding risk procedures, the international normalized ratio needs to be evaluated before the procedure. The average therapeutic range of INR for the cardiac patient is $2.0-3.0$. If the INR is more than 3.5, then dose adjustments have to be planned. During that case, the procedure must be delayed till the patient's INR is reduced to 3.5 or even less than that. ${ }^{17}$

\section{NOVEL ANTICOAGULANTS}

To overcome the limitations of heparin and warfarin, new anticoagulant drugs were introduced in 2008.17,18 They specifically target the selective steps in the coagulation cascade. They include apixaban, rivaroxaban and edoxaban, which are direct factor Xa inhibitors and dabigatran, which is a direct thrombin inhibitor. ${ }^{19}$ These drugs are indicated in cases of deep vein thrombosis, stroke, for the prevention of thromboembolic events and in the management of acute coronary syndromes. Rivaroxaban and edoxaban are usually 
taken once daily, whereas apixaban and dabigatran are taken twice daily. These drugs have a wide therapeutic range, no food interactions, compared to warfarin, lesser risk of intracranial bleeding, rapid onset of action, stability at a fixed dose and no need for regular monitoring. Only the renal function has to be tested before the initiation of the drugs. It is contraindicated in cases of renal impairment, history of gastric bleeding or ulcer, hepatic disorders and in pregnancy, breastfeeding individuals. ${ }^{20}$

There is no specific evidence-based guideline for the management of dental patients under NOAC. A recent evidence-based review reports that there is a lack of good quality studies pertaining to dental procedures in patients under NOACs. ${ }^{21}$ Based on the currently available evidence, simple surgical interventions that have low bleeding risk can be done without interruption of DOACs in patients with normal renal function. The procedures should be done 12 or 24 hours after the last intake.

Interventions at peak plasma concentration should be avoided. ${ }^{22}$ In case of a high risk of bleeding, it is advisable to delay the morning dose on the day of dental treatment. NOACs can be continued again after 6 to 8 hours after the dental intervention. ${ }^{22,23}$ Due to the short time to peak plasma concentration of DOACs, resuming the drug at the same dose once haemostasis has been established provides rapid restoration of anticoagulation after the intervention. ${ }^{24}$

The disadvantages of NOACs include the lack of an antidote to resolve major bleeding complications possibly associated with their ubiquitous use. ${ }^{25}$ The periprocedural management of patients on NOACs is a complex clinical problem and may pose a patient-specific concern. The cost of these drugs was comparatively higher than VKA. Since most of the NOAC agents are renally eliminated, the patients with a renal impairment will be benefited. ${ }^{26}$

\section{Dabigatran}

Approved by the EU in 2008 and FDA in 2010. It was the first NOAC of its class $^{27}$ It is a direct thrombin inhibitor that prevents the conversion of fibrinogen to fibrin, which leads to the prevention of clot formation. It has poor absorption through the gastrointestinal tract. Therefore, it is given as the prodrug dabigatran, edoxaban. Its bioavailability is $3-7 \%$. It takes 1 - 3 hours to achieve the peak concentration. It's halflife is $12-17$ hours.

The normal dosing regimen would be $110-150 \mathrm{mg}$ twice daily. It is indicated in cases of stroke prevention in nonvalvular atrial fibrillation, venous thromboembolism treatment and in its prevention. It does not require routine monitoring. ${ }^{28}$

\section{Rivaroxaban}

It is a Factor Xa inhibitor with $80 \%$ of bioavailability. ${ }^{29}$ Its half-life is 7 - 13 hours. There is no documentation of drug-todrug interactions and with other medications. Most of the drugs around 1 / 3rd will be eliminated by the kidneys and the remaining part will be eliminated by the hepatobiliary route. Patients with hepatic or renal impairment should be assessed carefully.
It takes 2 - 4 hours to reach the peak concentration. The dosing regimen would be $10-20 \mathrm{mg}$ once daily, $15 \mathrm{mg}$ once or twice daily. ${ }^{30}$ Its indications include stroke prevention in non - ventricular atrial fibrillation, venous thromboembolism management, recurrent VTE prevention, prophylaxis of VTE following hip or knee replacement. ${ }^{31}$

\section{Apixaban}

It is a Factor Xa inhibitor with a half-life of 8 - 10 hours. It takes $1-3$ hours to reach the peak concentration. It can be used in patients with renal insufficiency because it is primarily eliminated via the faecal route. The remaining small portions were metabolized via the cytochrome P450 3A4 dependent pathway in the liver and the rest $25 \%$ via urine. But there were no previous comparative studies to substantiate this evidence. ${ }^{32}$ Dosing regimen would be $2.5-5$ mg twice daily. Its renal clearance rate is $25 \%$. It is also indicated in cases of stroke prevention in non-ventricular atrial fibrillation, prophylaxis of venous thromboembolism following a hip or knee replacement. ${ }^{33,34}$

\section{Edoxaban}

It is a factor Xa inhibitor with a half-life of 8 - 10 hours. ${ }^{35}$ More than one-third of drugs will be eliminated renally. The reduced dose can be recommended for patients with renal insufficiency in which creatinine clearance was $30-50 \mathrm{~mL} /$ min. Similar to other Factor Xa inhibitors, it does not require regular monitoring. ${ }^{36}$ It has $62 \%$ of bioavailability. The dosing regimen would be 15 - $30 \mathrm{mg}$ once daily. It has $35 \%$ of renal clearance. Its indications include the prevention of risk of stroke and systemic embolism in patients with nonventricular atrial fibrillation and venous thromboembolism treatment. ${ }^{37}$

Assessment of difference between postoperative bleeding complications of NOAC and vitamin $\mathrm{k}$ antagonists -

All the studies relevant to bleeding risk in patients on NOAC and VKA were reviewed. A prospective cohort study conducted by Schifter et al. ${ }^{38}$ consisted of 107 patients in which 81 were under NOAC and 21 were under warfarin therapy. The study measured the post-operative bleeding by the weight difference in gauze before and after biting to estimate the blood loss. Results stated that dental extractions on patients continuing NOAC led to blood rates similar to patients on warfarin with an INR between 2.0 - 4.0. A study with a maximum sample size of 541 (72 - under NOAC, 100 under VKA and 67 - not taking anticoagulants) stated that the risks of post-extraction bleeding were similar for NOAC and vitamin $\mathrm{K}$ antagonist groups. ${ }^{39}$

A study reported that dental extractions can be performed safely on patients with NOAC with the help of haemostatic agents without any stoppage or alternation of oral anticoagulant therapy. It was a prospective observational study with a sample size of 51 patients but the measurement of postoperative bleeding was not mentioned. ${ }^{38,40}$ A study conducted by Yasaka. $\mathrm{M}$ et al. ${ }^{41}$ stated that the interruption of NOAC therapy was not necessary for tooth extractions if the procedure was performed at least six hours after the last dose.

But, Yasaka et al. Rizzo. R et al. ${ }^{41,42}$ reported that bleeding events were not statistically significant for both NOAC and 
vitamin $\mathrm{K}$ antagonist groups. He also added that they were not clinically relevant. Similarly, Bispo AF et al. ${ }^{43}$ reported that there was no significant difference between these two groups. In this study, bleeding time was measured between the end of sutures and the complete hemostasis. ${ }^{44}$ In a study, dabigatran and warfarin administration were interrupted 49 hours and 114 hours preoperatively. Bleeding rates were similar between both groups.

A study conducted by ${ }^{24}$ analyzed whether the medical practitioners regarding the recognition and correct approach towards novel anticoagulants. $12 \%-50 \%$ of medical practitioners failed to identify the NOAC drugs, remaining 50 $\%$ recognized the drugs but they failed to take the appropriate decision about continuing the drugs before an invasive procedure. Decisions on continuation or discontinuation of these drugs before the invasive dental procedure should be made in consultation with the cardiologist. 45 It is reported that $1.05 \%$ of complication was determined by thromboembolism and a rate of $0.53 \%$ was related to major bleeding incident rates. This study had a sample size of 190 patients with venous thromboembolic disorders. However, there is a lack of clear indications about the alternation or continuation of the NOAC and VKA therapies during the dental procedures. Large clinical prospective cohort studies were recommended to overcome this fact. ${ }^{20}$

\begin{tabular}{|c|c|c|}
\hline $\begin{array}{l}\text { Dental Procedures } \\
\text { That are Unlikely to } \\
\text { Cause Bleeding }\end{array}$ & $\begin{array}{l}\text { Low Bleeding Risk } \\
\text { Dental Procedures }\end{array}$ & $\begin{array}{c}\text { High Bleeding Risk Dental } \\
\text { Procedures }\end{array}$ \\
\hline $\begin{array}{l}\text { Infiltration, } \\
\text { intraligamentary or } \\
\text { mental nerve block by } \\
\text { Local anaesthesia }\end{array}$ & $\begin{array}{l}\text { Extractions of } 3 \text { or less } \\
\text { than } 3 \text { teeth }\end{array}$ & $\begin{array}{l}\text { Complex extractions, adjacent } \\
\text { extractions that will cause a large } \\
\text { wound, or more than three } \\
\text { extractions at once }\end{array}$ \\
\hline $\begin{array}{l}\text { Local anaesthesia by } \\
\text { inferior alveolar nerve } \\
\text { block or other regional } \\
\text { nerve block }\end{array}$ & $\begin{array}{l}\text { Incision and drainage of } \\
\text { intraoral swelling }\end{array}$ & $\begin{array}{l}\text { Flap raising procedures include } \\
\text { Elective surgical procedures } \\
\text { Periodontal surgery } \\
\text { Pre-prosthetic surgery } \\
\text { Peri radicular surgery } \\
\text { Crown lengthening } \\
\text { Dental implant surgery }\end{array}$ \\
\hline $\begin{array}{c}\text { Basic periodontal } \\
\text { examination }\end{array}$ & $\begin{array}{c}\text { Detailed six-point full } \\
\text { periodontal examination }\end{array}$ & Gingival recontouring \\
\hline $\begin{array}{l}\text { Supragingival removal of } \\
\text { plaque, stains and } \\
\text { calculus }\end{array}$ & $\begin{array}{c}\text { Root surface } \\
\text { instrumentation (RSI) }\end{array}$ & Biopsies \\
\hline $\begin{array}{l}\text { Direct or indirect } \\
\text { restorations with } \\
\text { supragingival margins }\end{array}$ & $\begin{array}{l}\text { Direct or indirect } \\
\text { restorations with } \\
\text { subgingival margins }\end{array}$ & \\
\hline \multicolumn{3}{|l|}{ Orthograde endodontics } \\
\hline \multicolumn{3}{|l|}{$\begin{array}{l}\text { Prosthetic procedures } \\
\text { like impressions }\end{array}$} \\
\hline \multicolumn{3}{|l|}{$\begin{array}{l}\text { Fitting and adjustment of } \\
\text { orthodontic appliances }\end{array}$} \\
\hline \multicolumn{3}{|c|}{$\begin{array}{c}\text { Table 1. Comprehensive Classification of Dental Interventions Based } \\
\text { on the Associated Bleeding Given by SDCEP (Scottish Dental } \\
\text { Effectiveness Programme) }\end{array}$} \\
\hline
\end{tabular}

\section{Interruption of Anticoagulants Prior to Dental Procedures}

The level of bleeding was dependent on the type of dental procedure. Table 1 represents the procedures associated with high, low and unlikely to cause bleeding risk. If the procedure comes under unlikely to cause bleeding, as mentioned earlier there is no need for the discontinuation of NOAC prior to dental procedures. One should also remember that discontinuation of NOAC depends on the individual anticoagulant drug. For example, dabigatran discontinuation time was specific to the patient's creatinine clearance. Patients with creatinine clearance of $50 \mathrm{~mL} / \mathrm{min}$ or more than that should stop the medication 24 - 48 hours prior to dental procedures. ${ }^{46}$ On the other hand, creatinine clearance less than $50 \mathrm{~mL} /$ min must discontinue the drug 3 - 5 drugs preoperatively. ${ }^{47}$ Discontinuation of rivaroxaban was unclear in the literature. In a comparison of apixaban with warfarin, there was no significant difference in bleeding risks between them. ${ }^{48}$ Other studies stated that apixaban should be stopped 48 hours before the high bleeding risk procedures and 24 hours before the low-risk bleeding procedures. ${ }^{49}$ After the haemostasis postoperatively, NOAC administration must be continued. In case of extensive bleeding, local haemostatic agents should be used. 50

Recommendations for patients under anticoagulants for dental treatment would be scheduling the procedure in the morning, estimation of international normalized ratio before the procedure, conservative surgical approach by performing single or less than three teeth extraction, in case of bleeding use of local haemostatic agents were recommended. Management of the patients can vary according to patient medication history and underlying systemic condition.51 For example, renal or hepatic impairment, thrombocytopenia, concomitant anticoagulants, antiplatelets, or non-steroidal anti-inflammatory drugs can influence the risk of bleeding.

\section{CONCLUSIONS}

Based on the evidence, it is clear that there is no significant difference between NOAC and VKA in causing post-operative bleeding risk following an invasive dental treatment. In case of bleeding after the invasive dental procedure, it can be controlled by local haemostatic agents. It is always the risk versus benefit for the discontinuation of anticoagulants.

Financial or other competing interests: None.

Disclosure forms provided by the authors are available with the full text of this article at jemds.com.

\section{REFERENCES}

[1] O'Brien JR. Some factors determining thrombus formation in acute coronary thrombosis. Prog Cardiovasc Dis 1958;1(2):151-64.

[2] Lamichhane M, Salehi N, Ahmadjee A, et al. Pathology of arterial thrombosis: characteristics and thrombus types. In: Topaz 0, ed. Cardiovascular thrombus. $1^{\text {st }}$ edn. Elsevier 2018:15-30.

[3] Lippi G, Franchini M, Targher G. Arterial thrombus formation in cardiovascular disease. Nat Rev Cardiol 2011;8(5):502-12.

[4] Hornstra G. Effect of type and amount of dietary fats on arterial thrombus formation. In: Hornstra G, ed. Dietary fats, prostanoids and arterial thrombosis. Springer 1982:44-62.

[5] Aldous JA, Olson CJ. Managing patients on warfarin therapy: a case report. Special Care in Dentistry 2001;21(3):109-12.

[6] Wang M, Zeraatkar D, Obeda M, et al. Drug - drug Interactions with Warfarin: a systematic review and meta - analysis. Br J Clin Pharmacol 2021. 
[7] Mannucci PM, Franchini M. Old and new anticoagulant drugs: a minireview. Ann Med 2011;43(2):116-23.

[8] Beyer-Westendorf J, Tittl L, Naue C, et al. NOAC Therapy is also Effective and Safe in Patients Older than 80 Years - Results of the Prospective Dresden NOAC Registry (NCT01588119). Hamostaseologie 2019;39(S 01):S1S92.

[9] Jackson LR, Becker RC. Novel oral anticoagulants: pharmacology, coagulation measures, and considerations for reversal. J Thromb Thrombolysis 2014;37(3):380-91.

[10] DeWald TA, Becker RC. The pharmacology of novel oral anticoagulants. J Thromb Thrombolysis 2014;37(2):21733.

[11] Bajkin BV, Popovic SL, Selakovic SDJ. Randomized, prospective trial comparing bridging therapy using low molecular - weight heparin with maintenance of oral anticoagulation during extraction of teeth. J Oral Maxillofacial Surg 2009;67(5):990-5.

[12] Chinnaswami R, Bagadia RK, Mohan A, et al. Dentists' knowledge, attitude and practice in treating patients taking oral antithrombotic medications - a survey. J Clin Diagn Res 2017;11(1):ZC88-91.

[13] Namis SM, Al - Habbab RY. A an evidence based practice guidelines for dental professionals to manage anticoagulant therapy patients seeking dental care: a review article. J Dent Max Surg 2019;2(1)107-10.

[14] Huang HK, Liu PPS, Lin SM, et al. Risk of developing diabetes in patients with atrial fibrillation taking non vitamin $\mathrm{K}$ antagonist oral anticoagulants or warfarin: a nationwide cohort study. Diabetes Obes Metab 2021;23(2):499-507.

[15] Biedermann JS, Rademacher WMH, Hazendonk HCAM, et al. Predictors of oral cavity bleeding and clinical outcome after dental procedures in patients on vitamin $\mathrm{K}$ antagonists. A cohort study. Thromb Haemost 2017;117(7):1432-9.

[16] Bacci C, Maglione M, Favero L, et al. Management of dental extraction in patients undergoing anticoagulant treatment. Results from a large, multicentre, prospective, case-control study. Thromb Haemost 2010;104(5):9725.

[17] Franchini M, Mengoli C, Cruciani M, et al. Effects on bleeding complications of pharmacogenetic testing for initial dosing of vitamin $\mathrm{K}$ antagonists: a systematic review and meta - analysis: reply. J Thromb Haemost 2015;13(6):1164-5.

[18] Skaistis J, Tagami T. risk of fatal bleeding in episodes of major bleeding with new oral anticoagulants and vitamin $\mathrm{K}$ antagonists: a systematic review and meta - analysis. PLoS One 2015;10(9):e0137444.

[19] Elad S, Marshall J, Meyerowitz C, et al. Novel anticoagulants: general overview and practical considerations for dental practitioners. Oral Dis 2016;22(1):23-32.

[20] Costantinides F, Rizzo R, Pascazio L, et al. Managing patients taking novel oral anticoagulants (NOAs) in dentistry: a discussion paper on clinical implications. BMC Oral Health 2016;16:5.

[21] Makam S, Kirticumar P, Somaia N, et al. Improving knowledge of novel oral anticoagulants amongst general dental practitioners. $\mathrm{Br} \quad \mathrm{J}$ Oral Maxillofac Surg 2019;57(10):e12

[22] Chaudhry S, Jaiswal R, Sachdeva S. Dental considerations in cardiovascular patients: a practical perspective. Indian Heart J 2016;68(4):572-5.

[23] Vinayak M, Sharma A. Dental considerations in cardiovascular patients: a practical perspective. Indian Heart Journal 2017;69(1):129.

[24] Olaiya A, Lurie B, Watt B, et al. An observational study of direct oral anticoagulant awareness indicating inadequate recognition with potential for patient harm. J Thromb Haemost 2016;14(5):987-90.

[25] Scott A, Gibson J, Crighton A. The management of dental patients taking new generation oral anticoagulants. Prim Dent J 2014;3(4):54-8.

[26] Kojima K. The comparison of direct oral anticoagulants (DOAC) and Warfarin for anticoagulation in the patients with gastrointestinal bleeding [Internet]. http://dx.doi.org/10.26226/morressier.59a6b344d462 b80290b5452d

[27] Blech S, Ebner T, Ludwig-Schwellinger E, et al. The metabolism and disposition of the oral direct thrombin inhibitor, dabigatran, in humans. Drug Metabol Dispos 2008;36(2):386-99.

[28] Stangier J, Rathgen $K$, Stähle $H$, et al. The pharmacokinetics, pharmacodynamics and tolerability of dabigatran etexilate, a new oral direct thrombin inhibitor, in healthy male subjects. Br J Clin Pharmacol 2007;64(3):292-303.

[29] Perzborn E, Roehrig S, Straub A, et al. Rivaroxaban: a new oral factor Xa inhibitor. Arterioscler Thromb Vasc Biol 2010;30(3):376-81.

[30] Kreuziger LMB, Morton CT, Dries DJ. New anticoagulants: a concise review. J Trauma Acute Care Surg 2012;73(4):983-92.

[31] Eriksson BI, Borris LC, Friedman RJ, et al. Rivaroxaban versus enoxaparin for thromboprophylaxis after hip arthroplasty. N Engl J Med 2008;358(26):2765-75.

[32] Kessler CM, Goldstein JN. A new strategy for uncontrollable bleeding after treatment with rivaroxaban or apixaban: Q\&A. Clin Adv Hematol Oncol 2019;17 Suppl 15(9):16-7.

[33] Neville R, Laredo J. Faculty Opinions recommendation of Apixaban or enoxaparin for thromboprophylaxis after knee replacement [Internet]. Faculty Opinions - Post Publication Peer Review of the Biomedical Literature. 2009.

[34] Lassen MR, Gallus AS, Pineo GF, et al. Randomized Double - blind comparison of apixaban with enoxaparin for thromboprophylaxis after knee replacement: the ADVANCE - 1 Trial. Blood 2008;112:31.

[35] Ruff CT, Giugliano RP, Antman EM, et al. Evaluation of the novel factor Xa inhibitor edoxaban compared with warfarin in patients with atrial fibrillation: design and rationale for the Effective aNticoaGulation with factor $\mathrm{xA}$ next GEneration in Atrial Fibrillation - Thrombolysis In Myocardial Infarction study 48 (ENGAGE AF - TIMI 48). Am Heart J 2010;160(4):635-41.

[36] Chao TF, Chen SA, Ruff CT, et al. Clinical outcomes, edoxaban concentration, and anti - factor Xa activity of Asian patients with atrial fibrillation compared with non - Asians in the ENGAGE AF - TIMI 48 trial. Eur Heart J 2019;40(19):1518-27. 
[37] Raskob G, Büller H, Prins M, et al. Edoxaban for the long term treatment of venous thromboembolism: rationale and design of the Hokusai - venous thromboembolism study - methodological implications for clinical trials. J Thromb Haemost 2013;11(7):1287-94.

[38] Brennan Y, Gu Y, Schifter M, et al. Dental extractions on direct oral anticoagulants vs. warfarin: The DENTST study. Res Pract Thromb Haemost 2020;4(2):278-84.

[39] Yagyuu T, Kawakami M, Ueyama Y, et al. Risks of postextraction bleeding after receiving direct oral anticoagulants or warfarin: a retrospective cohort study. BMJ Open 2017;7(8):e015952.

[40] Mauprivez C, Khonsari RH, Razouk O, et al. Management of dental extraction in patients undergoing anticoagulant oral direct treatment: a pilot study. Oral Surg Oral Med Oral Pathol Oral Radiol 2016;122(5):e146-55.

[41] Yoshikawa H, Yoshida M, Yasaka M, et al. Safety of tooth extraction in patients receiving direct oral anticoagulant treatment versus warfarin: a prospective observation study. Int J Oral Maxillofac Surg 2019;48(8):1102-8.

[42] Berton F, Costantinides F, Rizzo R, et al. Should we fear direct oral anticoagulants more than vitamin $\mathrm{K}$ antagonists in simple single tooth extraction? A prospective comparative study. Clin Oral Investig 2019;23(8):3183-92.

[43] Andrade MVS, Andrade LAP, Bispo AF, et al. Evaluation of the Bleeding Intensity of Patients Anticoagulated with Warfarin or Dabigatran Undergoing Dental Procedures. Arq Bras Cardiol 2018;111(3):394-9.

[44] Healey JS, Eikelboom J, Yang S, et al. Response to letters regarding article, "Periprocedural bleeding and thromboembolic events with dabigatran compared with warfarin: results from the Randomized Evaluation of Long - Term Anticoagulation Therapy (RE - LY) Randomized Trial." Circulation 2013;127(11):e506.

[45] Shaw JR, Woodfine JD, Douketis J, et al. Perioperative interruption of direct oral anticoagulants in patients with atrial fibrillation: A systematic review and meta analysis. Res Pract Thromb Haemost 2018;2(2):282-90.

[46] Lepilin AV, Parfenyuk GV. Small bleeds in elderly patients who are on prolonged anticoagulant therapy with new oral anticoagulants, before and during tooth extraction. Rossiiskaya Stomatologiya 2019;12:7.

[47] Boehringer Ingelheim is recalling a single lot of Pradaxa [dabigatran etexilate] $75 \mathrm{mg}$ capsules due to a potential packaging defect. Reactions Weekly 2012:p. 3.

[48] Lopes RD, Garcia DA, Wojdyla D, et al. Use of apixaban and warfarin in patients undergoing invasive procedures: insights from ARISTOTLE. European Heart Journal 2013;34(Suppl 1):535.

[49] Inc. KN, Kernel Networks Inc. Human medicines European public assessment report (EPAR): Eliquis, apixaban, Arthroplasty,Venous Thromboembolism, Date of authorisation: 18 / 05 / 2011, Revision: 17, Status: Authorised [Internet]. Case Medical Research. 2019.

[50] Caliskan M, Tukel HC, Benlidayi E, et al. Is it necessary to alter anticoagulation therapy for tooth extraction in patients taking direct oral anticoagulants? Med Oral Patol Oral Cir Bucal 2017;22(6):e767-73.

[51] Pippi R, Scorsolini MG, Luigetti L, et al. Tooth extraction without discontinuation of oral antithrombotic treatment: a prospective study. Oral Dis 2021;27(5):1300-12. 